\title{
The mobility of older people - An introduction
}

\author{
Tim Schwanen ${ }^{1}$ \\ Antonio Páez ${ }^{2}$ \\ ${ }^{1}$ Transport Studies Unit \\ School of Geography and the Environment \\ University of Oxford \\ South Parks Road \\ Oxford, OX1 3QY, UK \\ E-mail address: tim.schwanen@ouce.ox.ac.uk \\ McMaster Institute for Transportation and Logistics \\ School of Geography and Earth Sciences \\ McMaster University \\ 1280 Main Street West \\ Hamilton, Ontario \\ Canada L8S 4K1 \\ E-mail address: paezha@mcmaster.ca
}

Journal of Transport Geography

Final version

May 2010 


\section{The mobility of older people - An introduction}

\section{Background}

Studies of how older people move through space as part of their daily round of such activities as shopping, socialising, leisure and unpaid work go back a long time (e.g. Carp, 1971; Hanson, 1977). Yet, in recent years mobility in old age seems to have caught the attention of more geographers, transport researchers, gerontologists, geriatricians and others than ever before (e.g. Marottoli et al., 1997; Metz, 2000; Rosenbloom, 2001; Waldorf, 2003; Banister and Bowling, 2004; Mollenkopf et al., 2005; Adler and Rottunda, 2006; Páez et al., 2007; Oxley and Wheelan, 2008; Siren and Hakamies-Blomqvist, 2009; Ziegler and Schwanen, 2010). A significant number of the recent contributions in this field have been published in the Journal of Transport Geography (e.g. Newbold et al., 2005; Golob and Hensher, 2007; Schmöcker et al., 2008; Mercado and Páez, 2009; Ipingbemi, 2010).

There are a number of substantive reasons that explain the growth of interest in aging and mobility. The most immediate one is the well documented fact that both the absolute number and share of older people are on the increase in many western countries and beyond. The implications of the travel patterns of older people for sustainability of urban environments and their demand for transportation services have been the subject of extensive discussion and speculation, but until recently only a very limited empirical base existed to support any contentions about the possible transportation impacts of demographic aging. From early on, it was more or less anticipated that seniors would travel in ways that differed from other age cohorts. The implications of the anticipated differences for sustainability, for instance, were explored by Rosenbloom (2001), whereas the mobility expectations of seniors were the topic 
of a paper by Alsnih and Hensher (2003). Research reported in the literature over the past ten years or so has made substantial progress in terms of broadening the existing knowledge base by studying aging and mobility systematically, in a variety of geographical settings, while controlling for a host of confounding effects (e.g., to disentangle mobility differences due to chronological age, as opposed to, say, retirement). An outcome of this stream of research has been to generate a much clearer picture of the specificity of older people's travel patterns relative to other age groups, compared to even a decade ago.

The existing literature indicates that on average, after controlling for many other variables, older people are more often immobile in the sense of not leaving the house on a given day, make fewer trips on days they go out, use non-car transport modes more frequently, and travel over shorter distances than do younger cohorts (e.g., Schwanen et al., 2001; Rosenbloom, 2004; Páez et al., 2007; Mercado and Páez, 2009; Hjorthol et al., this issue; Roorda et al., 2010). They also tend to travel less outside peak hours or at night (Hanson, 1977; Scott et al., 2009). While some of these patterns reflect the impact of retirement, changes in lifestyle, and bodily ageing on time use and activity participation (Hanson, 1977), after controlling for employment status and other confounders, many studies still find that there are age-specific mobility effects. These effects, moreover, are far from homogenous. While the picture of the immobile senior is fairly typical, the literature also emphasises that older people's travel behaviours are not by any means uniform. In fact, large differences among seniors have been documented in trip frequency, travel distance and mode choice, depending for example on place of residence and mode of transport used (e.g., Schwanen et al., 2001; Páez et al., 2007; Roorda et al., 2010). These within-cohort differences are investigated partly structured according to such factors as gender, ethnicity, dis/ability, residential location, and social and support networks, among others. The large heterogeneity 
observed among seniors represents an unprecedented situation that poses important challenges for transportation planning and policy (Metz, 2003; Páez et al. 2007).

Two important questions emerge in consideration of demographic aging and transportation. First, how will the rise of the $65+$ cohort and its specific mobility traits affect transport and land use systems? And secondly, how will those systems affect the mobility of older people? A key concern with regards to the first question is the traffic safety situation of older drivers. In many western countries older drivers are functionally dependent on their private cars for most or all of their mobility needs; their presence on the roads on the other hand has increasingly become a top concern for road authorities the world over. Their lower mobility and car use notwithstanding, older people tend to be at greater risk of injury and fatality in traffic than other age groups, which is caused among others factors by their greater physical vulnerability (Hakamies-Blomqvist, 2004). Statistics also indicate that older drivers are more likely to be involved in crashes, especially on a per kilometre basis. As Oxley and colleagues in their contribution explain, this "older driver problem" stems in part from the geography of older people's driving practices: they are more likely to travel within urban areas, which exposes them to the challenge of negotiating intersections, and less on motorways and settings that require fewer overall manoeuvres. With regards to the second question, the lower levels of mobility observed among older people are a source of growing concern among researchers and professionals; in particular, this seems to affect those seniors who are no longer able or willing to drive, and who lack the support networks to compensate for their loss of independent mobility. While it is certainly possible that reduced mobility could be a matter of preference or taste, we should not ignore the fact that low mobility could in fact be an undesired effect of aging, and therefore problematic if it reduces older people's participation in social, economic, leisure, and cultural activities below preferred levels, with 
the consequent decrease in quality of life (Metz, 2000; Banister and Bowling, 2004; Páez et al., 2009). Of the various aspects that require attention as we strive to develop a more complete understanding of aging and mobility, we argue that the context and interactions surrounding the ability of old people to travel should be among the top priorities in the research agenda.

\section{Contextuality}

One of the achievements of the recent burgeoning of academic interest in the past decade is that 'the big picture' of current and future developments in mobility in old age is now reasonably well-known. Perhaps less understood is, we suggest, how context is implicated in and shapes those developments. The existing literature does suggest that travel patterns in old age and their relationships with such factors as gender or ethnicity vary across geographical space, but draws disproportionally on data from urban areas in North America, North-western Europe and Australia, and to the extent that research has been published in the international literature, from Japan (e.g. Doi et al., 2008). The mobility of older people in rural areas in some of the same parts of the world has been studied (e.g. Hough et al., 2008; Ziegler and Schwanen, 2010) but has attracted less attention. Very little is known about older people outside the Western world. A few studies are available and have worked around the constraints imposed by the costs and availability of appropriate data in developing and newly industrialised countries; examples include Turner and Kwakye (1996) on Accra, Ghana, and Ipingbemi (2010) on Ibadan, Nigeria. Work along these lines shows important differences, as well as similarities, with studies in Western countries and should be undertaken more often, if only because the ageing of the population follows unique development trajectories in 
different geographical contexts. One should not assume that developing countries and newly industrialised countries will exhibit the same trends with regard to ageing and mobility in the future that Western countries have experienced and currently experience. But context is more than geographical specificity. While it is a difficult concept that means different things to different people, we think it bears on mobility in old age in at least two further ways: it helps us to make sense of the heterogeneity of the mobility practices and experience of different older people and to think more critically about the nature of ageing and old age. With regard to the first point, Páez and Scott (2007) remark that "the next step towards a more refined understanding of travel behaviour will take as a starting point the proposition that human beings are social animals." The selfsame sentiment is expressed by Hanson in recent remarks stating that "mobility is not just about the individual (as so much of the literature would have us believe) but about the individual as embedded in, and interacting with, the household, family, community and larger society" (2010, page 8). Others have made similar points (e.g. Law, 1999; Cresswell, 2006; Kwan, 2007). Mobility in old age can thus be expected to be deeply contextual. Exactly what this contextuality entails is an empirical question but context is likely to comprise the following dimension identified in Hanson (2010) and Schwanen et al. (2008): 1) the social relations of household, family, friends, acquaintances and community; 2) the built environment, including transport, communication and other infrastructures; 3) the configuration of institutions responsible for the built environment, policies and other forms of regulation; and 4) the cultural norms and expectations that underpin travel practices and the regulation of mobility. To these we may add a temporal-path dimension, i.e. the stock of past events and experiences and orientations towards the future of individuals, households, families, communities and societies. This dimension may be of particular salience to older people, among other reasons because they have a temporally more extended memory than people in other age categories, and tend to have different dispositions towards the future than 
in earlier life stages (Heikkinen, 2004). Furthermore, a difference in disposition must be coupled with earlier life events (e.g. buying a car, deciding on a suburban residence) that may have prevented a range of experiences now requiring learning to adapt (e.g. using transit systems).

It is in the specifics of the interplay of these dimensions in particular spaces and times that differences in mobility in old age between places and between individuals emerge. Not all dimensions of context have, however, been given equal attention in past quantitative studies in geography and transport research. The built environment dimension seems to have acquired pre-eminence relative to the others: the effects of the intensity and diversity of land use (i.e. density and mixed land use) as well as access to transport infrastructures have been scrutinised more frequently (e.g. Schwanen et al., 2001; Waldorf, 2003; Banister and Bowling, 2004; Hess, 2009; Mercado and Páez, 2009). The institutional, temporal, social and cultural dimensions of context have been examined less frequently and less directly, although factors related to each have been drawn upon to explain observed differences in travel behaviour between groups of older people defined in terms of chronological age, gender, ethnicity, residential location, and so on. ${ }^{1}$

\section{The interdependence of mobility and old age}

It is also in the interplay of the aforementioned contextual dimensions that factors like gender, ethnicity, age or physical functioning and corporeal competences obtain meaning in relation

\footnotetext{
${ }^{1}$ It should be noted, however, that the institutional and social dimensions have been examined in considerable detail in some studies of driving reduction and cessation in such disciplines as gerontology and nursing research (e.g. Johnson, 1998; Friedland et al., 2006; Donorfio et al., 2008; see also below).
} 
to mobility. For not only is mobility contextual, so is age. It is fair to say that in many studies about the mobility of older people in transport geography and transport studies more widely 'old age' is treated as if it were an unproblematic category, one with a stable meaning that is transferable across space and time and can be approximated reliably using chronological criteria (i.e. age in years). This rather straightforward treatment of age differs from the notion now dominant in other parts of geography, and also in social gerontology, that the meaning and definition of 'old age' and 'ageing' are culturally and geographically variable and socially constructed (e.g. Harper and Laws, 1995; Hopkins and Pain, 2007). Paraphrasing Hanson (2010), we may say that the existing transport-related literature has been more successful in establishing how chronological old age shapes mobility than how mobility shapes age. Nonetheless, that literature provides numerous clues of how mobility is one arena where age as a social process and expression of inequalities is produced, in addition to the household, labour market, popular culture and media, the state and government, healthcare and the built environment (cf. Laws, 1995). $2^{2}$

This point can be exemplified using the academic literature about driving in later life, which is a key site for the production of old age. For many older car drivers, the use of the car becomes less self-evident at some moment during the life-course. They may even have to give up driving altogether. This process may be abrupt and occur after some event, such as an illness, accident or a fall, or be more gradual. It may result from self-regulation, from pressure by children or other family, from advice by physicians or social workers or be enforced by institutions (cf. Johnson, 1998; Bauer et al., 2003; Friedland et al., 2006; Donorfio et al., 2008). Mercado and colleagues in their contribution to this issue describe the chronological age-based driving licensing and renewal policy in the Canadian province of Ontario, which includes a mandatory vision test, knowledge test, driving record review and

\footnotetext{
${ }^{2}$ In fact, mobility can be thought as an area that provides important linkages between the other arenas.
} 
driver education programme. Other jurisdictions and countries have schemes of evaluating driving aptitudes of people above a certain chronological age that differ to greater or lesser degree from Ontario's. Yet, all originate from concerns about the traffic safety consequences of driving at advanced age among government bodies and other institutional actors. All are also ultimately rooted in a particular, biomedical discourse about ageing, according to which ageing is a process of inevitable incremental decline in people's physical, visual and cognitive capacities (cf. Estes, 2001). By defining who is entitled to drive and by promoting certain driving practices in people depending on their bodily competences, these schemes enact old age in a certain way: they co-create aged mobile subjectivities, i.e. age-based, possible ways of being, experiencing and moving through space that often have significant impacts on people's everyday life.

The triggering of driving reduction or cessation related to traffic safety concerns is justified if it occurs in persons whose corporeal capacities are well below norms of what is considered safe. But the situation is different if it occurs in older people whose aptitudes do not demand driving reduction or cessation: people may become unnecessarily disempowered. Either way, the result of driving reduction and cessation is often increased immobility and reduced wellbeing (e.g. Harrison and Ragland, 2003; Davey, 2007; Ziegler and Schwanen, 2010) although this too is mediated by context. Several studies suggest that women often adapt better to life-after-the-car than men and explain this through men's more extensive driving history and cultural norms that associated - and perhaps still associate - men and masculinity with being the primary driver (e.g. Bauer et al., 2003; Hakamies-Blomqvist and Siren, 2003).

The extent to which driving reduction and cessation have adverse effects may also depend on the configuration of the built environment - i.e. accessibility to services and other 
destinations and access to transport modes other than the car -, experiences with using noncar modes earlier in the life-course, experience with using digital communication technologies, people's social relations with family and friends and so on. Nonetheless, the literature does show that for many older men and increasingly also women car ownership and use have distinctive and unique meanings and relations with sense of self. Car use, for them, is more than simply being able to move from A to B; it is an expression of, and means towards, independence, autonomy, spontaneity, control and competence and thus enhances their wellbeing. Losing the ability to drive then becomes a symbol of incompetence, of a final rite of passage, of becoming old (Persson, 1993; Adler and Rottunda, 2006; Ziegler and Schwanen, 2011). For many, driving is one way of prolonging middle age and of enacting the cultural idea of the ageless self (Kaufman, 1986; McHugh, 2003).

This brief reflection on driving in later life suggests at least three things. First, age and mobility are implicated in one another. Age emerges out of the manifold mobility-related interactions between people with varying corporeal capacities and dates of birth, cars and other means of transport, infrastructures and built environments, institutional actors, and so on. This age is an always already situated process through which changes in bodies and their capacities over the life-course obtain meaning and significance and are translated in inequalities in mobility in particular place and times. Second, this age cannot readily be separated from other processes of sociospatial differentiation $3^{3}$, such as gender and ethnicity; it intersects with them (McCall, 2005; Hopkins and Pain, 2007). This implies that analysis of mobility in old age should simultaneously be examinations of gender, ethnic and other differentiations in mobility.

\footnotetext{
${ }^{3}$ We use the term sociospatial rather than social differentiation to emphasize that society and space are inextricably linked to, and constitutive of, each other.
} 
Third, given the complex interdependence of old age and mobility, we advocate a pluralistic approach (Longino, 2002) to the academic study of mobility in later life, i.e. one where researchers employ different theoretical perspectives, use different epistemologies, methodologies and methods, and study different facets of the object of interest in such a way that no perspective, methods or facets should take precedence over any of the others. In addition, researchers working within a particular theoretical, epistemological, methodological and/or disciplinary tradition should be open to learning about and from, and engage in debate with, other approaches. These requirements should be met, we think, if we are to truly understand the complexity of mobility in old age.

\section{Introducing the contributions}

Rather than describing each article in this special issue, we limit ourselves to a few general remarks. First, as a set, the papers presented here provide the pluralism in theoretical perspective, methodology and facet of mobility in later life advocated above. For instance, Burnett and Lucas (this issue) draw on the mobilities literature (Cresswell, 2006; Sheller and Urry, 2006) and use qualitative methods to examine the interrelations of mobility, immobility and social participation. This is in interesting contrast with, for instance, the contribution by Shoval et al. (this issue), who introduce a quantitative methodology based on GPS tracking devices and theoretically grounded in time-geography for the study of mobility and immobility in older people with different levels of cognitive function. Second, some papers highlight how old age intersects with other process of sociospatial differentiation. Shoval et al. examine how gender and cognitive ability in combination with chronological age affect mobility; Hjorthol et al. (this issue) analyse how gender and old age co-shape mobility and 
how the relations between mobility, age and gender develop over time in slightly different ways in three Nordic countries. Rosenbloom (this issue) shows how ethnicity mediates the ways in which adult children perceive and intervene in the mobility of their elderly parents.

Lastly, the contributions help to advance our understanding of how context mediates both mobility and old age. Petterson and Schmöcker (this issue) expand the geographical scope of research about mobility in old age, by analysing the travel patterns of older people in Manila and contrasting these with the situation in London. They also analyse how the built environment (i.e. population density) affects travel patterns in later life. Rosenbloom highlights the embeddedness of mobility in later life in social relations of family life, and Hjorthol et al. explain some of the changes in travel patterns they observe by referring to changes in cultural norms and values. The institutional dimension of context is foregrounded in Oxley et al. (this issue) and Mercado et al. (this issue). The former outlines, among others, the 'safe systems' approach developed in Australasia, which seeks to minimise crashes and their consequences for (older) road users and so provide safe (car) mobility in later life. Lastly, Mercado and colleagues (this issue) critically evaluate how public authorities in the Canadian province of Ontario provide diverse mobility options to an increasingly diverse elderly population.

\section{Concluding remarks}

We hope that the research collected in this special issue will become a valuable addition to the literature in terms of improving our understanding of mobility in aging, and the planning and policy responses that this phenomenon requires. As a final thought, we also feel it is 
important to remark that continued ageing of the population does not necessarily imply more of the same in mobility terms: the travel patterns of future generations of elderly will likely differ from current and previous ones, perhaps in ways that are now difficult to anticipate. Car use and distance travelled among the elderly, and especially among older women, have increased substantially in recent decades and these developments are likely to continue (e.g. Banister and Bowling, 2004; Rosenbloom, 2004; Hjorthol et al., this issue). Various explanations have been provided for these developments, including better health and physical capacities, higher incomes and levels of education, and personal histories of more car-based mobility in younger and future generations of older people. Culturally inflected expectations also differ between generations and may explain (expected) trends; many baby boomers have experienced "seamless affordable mobility, new technology, high style and a constant promise of improvement" throughout their lives (Coughlin, 2009, page 302). Whether these expectations can be fulfilled in a world increasingly strapped for material resources remains to be seen. In our view, this constitutes a call for a continued stream of research in order to ascertain whether changes occur over time and to identify the best ways to address the imperative of ensuring that our seniors can live rewarding, plentiful, and inclusive lives, all the while preventing the emergence or development of further strains on natural and social environments.

\section{References}

Adler, G., Rottunda, S., 2006. Older adults ee perspectives on driving cessation. Journal of Aging Studies 20 (3), 227-235.

Alsnih, R., Hensher, D. A., 2003. The mobility and accessibility expectations of seniors in an aging population. Transportation Research Part A 37 (10), 903-916.

Banister, D., Bowling, A., 2004. Quality of life for the elderly: the transport dimension. Transport Policy 11 (2), 105-15.

Bauer, M.J., Rottunda, S., Adler, G., 2003. Older women and driving cessation. Qualitative Social Work 2 (3), 309-325.

Carp, F.M., 1971. Walking as a means of transportation for retired people. The Gerontologist 11 (2 Part 1), 104-111. 
Coughlin, J.F., 2009. Longevity, lifestyle, and anticipating the demands of aging on the transportation system. Public Works Management \& Policy 13 (4), 301-311.

Cresswell, T., 2006. On the Move: Mobility in the Modern Western World. Routledge, New York. Davey, J.A., 2007. Older people and transport: coping without a car. Ageing \& Society 27 (1), 49-65.

Doi, K., Kii, M., Nakanishi, H., 2008. An integrated evaluation method of accessibility, quality of life, and social interaction. Environment and Planning B: Planning and Design 35 (6), 1098-1116.

Donorfio, L.K.M., Mohyde, M., Coughlin, J., D“eAmbrosio, L., 2008. A qualitative exploration of self-regulation behaviour among older drivers. Journal of Aging \& Social Policy 20 (3), 323-339.

Estes, C.L. et al., 2001. Social Policy \& Aging: A Critical Perspective. Sage, Thousand Oaks, CA.

Friedland, J., Rudman, D.L., Chipman, M., Steen, A., 2006. Reluctant regulators: perspectives of family physicians on monitoring seniors ${ }^{e e}$ driving. Topics in Geriatric Rehabilitation 22 (1), 53-60.

Golob, T.F., Hensher, D.A., 2007. The trip chaining activity of Sydney residents: A cross-section assessment by age group with a focus on seniors. Journal of Transport Geography 15 (4), 298-312.

Hakamies-Blomqvist, L., 2004. Safety of older persons in traffic. In: Transportation Research Board, ed., Transportation in an Aging Society: A Decade of Experience, pp. 22-35. TRB, Washington, D.C.

Hakamies-Blomqvist, L., Siren, A., 2003. Deconstructing a gender difference: driving cessation and personal driving history of older women. Journal of Safety Research 34 (4), 383-388.

Hanson, P., 1977. The activity patterns of elderly households. Geografiska Annaler, Series B: Human Geography 59 (2), 109-24.

Hanson, S., 2010. Gender and mobility: new approaches for informing sustainability. Gender, Place and Culture 17 (1), 5-23.

Harper, S., Laws, G. 1995. Rethinking the geography of ageing. Progress in Human Geography 19 (2), 1999-221.

Harrison, A., Ragland, D. 2003. Consequences of driving reduction or cessation for older adults. Transportation Research Record 1843, 96-104.

Heikkinen, R.-L., 2004. The experience of ageing and advanced old age: a ten-year follow-up. Ageing \& Society, 24 (4), 567-582.

Hess, D.B., 2009. Access to public transit and its influence on ridership for older adults in two U.S. cities. Journal of Transport and Land Use 2 (1), 3-27.

Hopkins, P., Pain, R., 2007. Geographies of age: thinking relationally. Area 39 (3), 287-294.

Hough, J.A., Cao, X., Handy, S.L. 2008. Exploring travel behavior of elderly women in rural and small urban North Dakota: an ecological modeling approach. Transportation Research Record 2082, $125-131$

Ipingbemi, O., 2010. Travel characteristics and mobility constraints of the elderly in Ibadan, Nigeria. Journal of Transport Geography 18 (2), 285-291.

Johnston, J.E., 1998. Older rural adults and the decision to stop driving: the influence of family and friends. Journal of Community Health Nursing 15 (4), 25-216.

Kaufman, S., 1986. The Ageless Self: Sources of Meaning in Late Life. Meridian, New York.

Kwan, M.-P., 2007. Mobile communications, social networks, and urban travel: hypertext as a new metaphor for conceptualizing spatial interaction. The Professional Geographer 59 (4), 434-446.

Law, R., 1999. Beyond „women and transporte: Towards new geographies of gender and daily mobility. Progress in Human Geography 23(4), 567-588.

Laws, G., 1995. Understanding ageism: lessons from feminism and postmodernism. The Gerontologist 35 (1), 112-118. 
Longino, H.E., 2002. The Fate of Knowledge. Princeton University Press, Princeton, NJ.

Marottoli, R.A., Mendes de Leon, C.F., Glass, T.A., Williams, C.S., Cooney Jr. L.M., Berkman, L.F.

Tinetti, M.E., 1997. Driving cessation and increased depressive symptoms: prospective evidence from the New Haven EPESE. Journal of the American Geriatrics Society 45 (2), 202-206.

McCall, L., 2005. The complexity of intersectionality. Signs 30 (3), 1771-1800.

McHugh, K., 2003. Three faces of ageism: society, image and place. Ageing \& Society 23 (2), 165-85.

Mercado, R., Páez, A., 2009. Determinants of distance traveled with a focus on the elderly: a multilevel analysis in the Hamilton CMA, Canada. Journal of Transport Geography 17 (1), 65-76.

Metz, D.H., 2000. Mobility of older people and their quality of life. Transport Policy 7 (2), 149-52.

Metz, D., 2003. Transport policy for an ageing population. Transport Reviews. 23 (4) 375-386.

Mollenkopf, H., Marcellini, F., Ruoppila, I., Széman, Z., Tacken, M., 2005. Enhancing Mobility in Later Life: Personal Coping, Environmental Resources and Technical Support. The Out-of-home Mobility of Older Adults in Urban and Rural Regions in Five European Countries. IOS Press, Amsterdam.

Newbold, K.B., Scott, D.M., Spinney, J. E.L., Kanaroglou, P., Páez, A., 2005. Travel behavior within Canada"s older population: a cohort analysis. Journal of Transport Geography 15 (4), 340-351.

Páez, A., Mercado, R.G., Farber, S., Morency, C., Roorda, M., 2009. Mobility and Social Exclusion in Canadian Communities: An Empirical Investigation of Opportunity Access and Deprivation, Report to

Policy Research Directorate, Strategic Policy and Research, Human Resources and Social Development

Canada. http://www.science.mcmaster.ca/geo/faculty/paez/publications.html\#reports

Páez, A., Scott, D.M., Potoglou, D., Kanaroglou, P.S., Newbold, K.B., 2007. Elderly mobility: demographic and spatial analysis of trip making in the Hamilton CMA. Urban Studies 44 (1), 123-146

Persson, D., 1993. The elderly driver: deciding when to stop. The Gerontologist 33 (1), 88-91.

Roorda, M., Páez, A., Morency, C., Mercado, R.G., Farber, S., 2010. Trip generation of vulnerable populations in three Canadian cities: a spatial ordered probit approach. Transportation 37 (3), 525-548.

Rosenbloom, S., 2001. Sustainability and automobility among the elderly: An international assessment. Transportation 28 (4), 375-408.

Rosenbloom, S., 2004. Mobility of the elderly: good news and bad news. In: Transportation Research Board, ed., Transportation in an Aging Society: A Decade of Experience, pp. 3-21. TRB, Washington, D.C.

Schmöcker, J.-D., Quddus, M.A., Noland, R.B., Bell, M.G.H., 2008. Mode choice of older and disabled people: a case study of shopping trips in London. Journal of Transport Geography 16 (4), 257-267

Schwanen, T., Dijst, M., Dieleman, F.M., 2001. Leisure trips of senior citizens: determinants of modal choice. Tijdschrift voor Economische en Sociale Geografie 91 (3), 347-360.

Schwanen, T., Dijst, M., Kwan, M.-P., 2008. ICTs and the decoupling of everyday activities, space and time: introduction. Tijdschrift voor Economische en Sociale Geografie 99 (5), 519-527.

Scott, D.M., Newbold, K.B., Spinney, J.E.L., Mercado, R., Páez, A., Kanaroglou, P.S., 2009. New insights into senior travel behavior: the Canadian experience. Growth and Change 40 (1), 140-68.

Sheller, M., Urry, J., 2006. The new mobilities paradigm. Environment and Planning A 38 (2), $207-$ 226. 
Siren, A., Hakamies-Blomqvist, L., 2009. Mobility and wellbeing in old age. Topics in Geriatric Rehabilitation 25 (1), 3-11.

Turner, J., Kwakye, E., 1996. Transport and survival strategies in a developing economy: case study evidence from Accra, Ghana. Journal of Transport Geography 4 (3), 161-168.

Waldorf, B., 2003. Automobile reliance among the elderly: race and spatial context effects. Growth and Change 34 (2), 175-201.

Ziegler, F., Schwanen, T., 2011. "I like to go out and be energised by different people": an exploratory analysis of mobility and wellbeing in later life. Ageing \& Society, forthcoming. 